\title{
Human isophane or lente insulin? A double blind crossover trial in insulin dependent diabetes mellitus
}

\author{
D M Gibb, A B M Foot, B May, H Parish, S Strang, D B Grant, D B Dunger
}

\begin{abstract}
Fifty two children with insulin dependent diabetes mellitus were randomised to receive human isophane or lente insulin preparations in combination with soluble insulin in a double blind trial. Patients were seen every two months, and crossed over after four months of treatment. Control assessed by glycated haemoglobin was significantly lower in children on human isophane insulin, but fasting blood glucose and fructosamine concentrations and the number of episodes of hypoglycaemia were similar on both regimens. In five children on twice daily insulin regimens, insulin profiles throughout a 24 hour period demonstrated greater variability on lente compared with isophane insulin despite identically administered insulin doses. A questionnaire completed at the end of the study showed that two thirds of the children and/or their parents preferred the isophane insulin, and they gave perceived improvement of metabolic control as the major reason for their choice.
\end{abstract}

Intermediate acting neutral crystalline protamine zinc insulin (isophane-also called neutral protamine Hagedorn insulin (NPH)) and insulin lente (zinc insulin) suspensions have been available for the last four decades. Both are frequently used in combination with short acting insulin in once or twice daily regimens in children with insulin dependent diabetes mellitus (IDDM). The consequences of mixing short (soluble) and intermediate acting insulins have only recently been thoroughly investigated. ${ }^{1-3}$ In adults with IDDM studies of the absorption, metabolic actions, and changes in plasma insulin concentrations have shown that lente insulin has a more protracted action than isophane insulin due to the loss of solubility of short acting insulin in the presence of excess zinc. ${ }^{34}$ There is some evidence that lente regimens may thus result in improved metabolic control in the early hours of the morning. ${ }^{56}$

Most trials that have formally compared isophane and lente insulins have been of low statistical power. ${ }^{7}$ Furthermore, the recent change from pork to human insulin with its different absorption kinetics has again raised the question of whether these two insulins are interchangeable. ${ }^{8}$ The only large trial comparing human isophane and lente insulins is that of Tunbridge $e t$ al who found no differences with respect to metabolic control or frequency of hypoglycaemic episodes between the two regimens in 82 adults with IDDM. ${ }^{9}$ There have been no comparison studies performed in children or adolescents, however, where the absorption kinetics may be different and the $C$ peptide status is more variable.

The aims of the present study were: (i) to compare the effects of human isophane (Protaphane, Novo) and lente (Monotard, Novo) insulin regimens on metabolic control and frequency of hypoglycaemia in children with IDDM, and (ii) to ascertain whether the children and parents participating in the study have any preference for one or other insulin regimen.

\section{Methods}

PATIENTS

Fifty two children attending the John Radcliffe Hospital, Oxford $(n=29)$ or the Hospital for Sick Children, Great Ormond Street, London $(n=23)$ for their diabetic care were enrolled into the study. The clinical characteristics of the children are shown in table 1 . Sixteen children had detectable $\mathrm{C}$ peptide in postprandial blood samples at entry into the study. The insulin dose and glycated haemoglobin concentrations of these children were similar to the children who were negative for $C$ peptide, but the soluble:intermediate insulin ratio was higher in the $\mathrm{C}$ peptide negative children (table 1). Thirteen children were on once daily and 39 were on twice daily insulin regimens. Forty two children were receiving pork lente or isophane insulin before commencing the study; the remaining children were receiving human insulin regimens.

TRIAL DESIGN

The trial was a double blind study with randomisation stratified for $\mathrm{C}$ peptide status and once/twice daily insulin regimen. Children were recruited one to two months before the beginning of the study and blood was drawn for $C$ peptide estimation. The nature of the study was explained, techniques for syringe mixing and injection of insulin were reviewed and retaught as necessary, and children and parents were taught how to take blood samples onto filter paper for fasting blood glucose estimation. They were encouraged to achieve optimal glycaemic control before the beginning of the study.

Stratification and randomisation was performed by Novo Laboratories Ltd and the pharmacy at each hospital was provided with insulins identified by code, but not by name. At entry and every two months thereafter, fasting 
Table 1 Characteristics of diabetic children by $C$ peptide status before randomisation

\begin{tabular}{llll}
\hline & $\begin{array}{l}C \text { peptide } \\
\text { positive } \\
(n=16)\end{array}$ & $\begin{array}{l}C \text { peptide } \\
\text { negative } \\
(n=36)\end{array}$ & $\begin{array}{l}\text { Total } \\
(n=52)\end{array}$ \\
\hline Median (range) age (years) & $10.9(5-18)$ & $13.1(8-18)$ & $11.6(5-18)$ \\
Median (range) disease duration (years) & $3.6(0.5-14)$ & $8.9(4-16)$ & $6.5(0.5-16)$ \\
Sex (M/F) & $6 / 10$ & $10 / 26$ & $16 / 36$ \\
Weight (kg)* & $41(11)$ & $43(15)$ & $43(14)$ \\
Insulin dose (U/kg)* & $1.0(0.2)$ & $0.90(0.2)$ & $0.93(0.2)$ \\
Once/twice daily insulin & $5 / 11(0.2)$ & $8 / 28$ & $13 / 39$ \\
Soluble:intermediate insulin ratio* & $0.3(0.2)$ & $0.5(0.3)$ & $0.4(0.3)$ \\
Glycated haemoglobin (g\%)* & $10.7(1.8)$ & $10.8(1.9)$ & $10.8(1.9)$ \\
Fructosamine (mmol/l)* & $4.6(0.4)$ & $4.1(0.9)$ & $4.3(0.3)$ \\
\hline
\end{tabular}

*Mean (SD).
$0.03 \mathrm{pmol} / \mathrm{ml}$. For measurement of plasma free insulin $1.0 \mathrm{ml}$ whole blood was added immediately to $0.6 \mathrm{ml}$ of ice cold $25 \%$ polyethylene glycol (Sigma) and samples were stored at $-4^{\circ} \mathrm{C} .11$ The insulin assay used was a single antibody radioimmunoassay with charcoal separation. ${ }^{12}$ Interassay coefficients of variation at $38 \cdot 0,49 \cdot 5,89 \cdot 0$, and $196 \cdot 6 \mathrm{pmol} / 1$ were $11 \cdot 0$, $7 \cdot 9,13 \cdot 6$, and $7 \cdot 9 \%$ respectively.

\section{STATISTICAL METHODS}

The primary endpoint was to ascertain whether isophane and lente insulin based regimens result in similar metabolic control as measured by glycated haemoglobin. Assuming a within individual standard deviation of $1.2 \mathrm{~g} \%$ in glycated haemoglobin, 48 children were required to detect a difference of $0.7 \%$ with a power of $90 \%$ at a significance level of $5 \%$.

Analysis of the data was undertaken using Statistical Analysis System (SAS Institute Inc). A two way analysis of variance was used to compare within individual values for glycated haemoglobin, fructosamine, and fasting blood glucose at the end of each treatment period, allowing for the effect of order of regimen administration. No order effect was observed, however, and therefore comparisons between the two regimens are presented using paired $t$ test.

Questionnaire data were analysed by comparing visual analogue scale scores using the Wilcoxon paired sign rank test. Data are presented as median differences and interquartile ranges. categorised into two sections: the first related to perceptions about metabolic control and frequency of hypoglycaemic episodes and the second to feelings about general well being, energy levels, and irritability on each insulin regimen. Visual analogue scales were utilised in the questionnare and consisted of $10 \mathrm{~cm}$ lines. Each line was scored from 1 to 100 with 100 representing the extreme negative pole (for example, very grumpy, etc) and one representing the extreme positive pole. Children were also asked to indicate an overall preference for one or other regimen.

The protocol was reviewed and passed by ethical committees at both participating hospitals.

\section{ANALYTICAL METHODS}

Glycated haemoglobin was measured by the agar electrophoretic method (Corning) with an interassay coefficient of variation of $4 \cdot 2 \%$. The reference range for healthy children was $4 \cdot 8-7 \cdot 1$ g\%. ${ }^{10}$ Serum fructosamine was measured colorimetrically (Roche Diagnostics), the interassay coefficient of variation being $2 \cdot 1 \%$ and normal range 2.6-3.3 mmol/1. Blood for fasting blood glucose estimation was taken onto filter paper impregnated with boric acid. After drying samples were sent to the Bristol Maternity Hospital for subsequent assay. After elution, glucose from the spots was measured by standard glucose oxidase method. Serum C peptide concentration was measured by radioimmunoassay, the lower limit of detection being
Results

Fifty one children completed the study. One child defaulted shortly after enrolment by not taking any intermediate acting insulin. Ten of the 13 children who were taking once daily insulin regimens at the start of the study were still on the same regimen at the end of the study. Three children changed to a twice daily regimen because of poor metabolic control: two while on the lente and one while on the isophane based insulin regimen.

Body weight, insulin dose, ratio of soluble to intermediate insulin, and ratio of morning to evening insulin dose at the end of each treatment period were similar on both the isophane and the lente based insulin regimens (table 2). Similarly, in the subgroup of five children admitted for $\mathbf{2 4}$ hour insulin profiles, there were no differences in insulin dose, ratio of soluble to intermediate insulin, or ratio of morning to evening insulin dose on the two regimens (table 3).

Mean (SD) glycated haemoglobin concentrations at the end of the isophane based insulin regimen was $11 \cdot 1(2 \cdot 2) \mathrm{g} \%$ and at the end of the lente based insulin regimen was $12.0(2 \cdot 2) \mathrm{g} \%$ (table 2). The within individual difference was $0.67 \mathrm{~g} \%$ (95\% confidence interval (CI) 0 to $1.35) \mathrm{g} \%$ lower on the isophane than on the lente based regimen $(p=0.05)$. This difference was similar if the $\mathrm{C}$ peptide positive children were excluded $(0.75 \mathrm{~g} \%$ (95\% CI 0 to 1.51$)$, 
Table 2 Comparison of isophane and lente insulin regimens. Values given as mean (SD)

\begin{tabular}{lcc}
\hline & $\begin{array}{c}\text { Isophane } \\
\text { insulin }\end{array}$ & $\begin{array}{c}\text { Lente } \\
\text { insulin }\end{array}$ \\
\hline Weight (kg) (U/kg) & $44 \cdot 8(15)$ & $45 \cdot 0(14)$ \\
Insulin dose & $1 \cdot 0(0 \cdot 2)$ & $1 \cdot 0(0 \cdot 2)$ \\
Soluble:intermediate insulin ratio & $0 \cdot 37$ & $0 \cdot 4$ \\
Morning:evening insulin ratio* & $2 \cdot 2$ & $2 \cdot 1$ \\
Glycated haemoglobin (g\%) & $11 \cdot 1(2 \cdot 2)$ & $12 \cdot 0(2 \cdot 2)$ \\
Fructosamine (mmol/) & $4 \cdot 0(0 \cdot 7)$ & $4 \cdot 0(0 \cdot 8)$ \\
Fasting glucose (mmol/l) & $8 \cdot 3(3 \cdot 8)$ & $8 \cdot 8(4 \cdot 6)$ \\
Hypoglycaemic episodes (total No episodes/No children): & $75 / 17$ & $110 / 23$ \\
Grade 1 & $141 / 36$ & $177 / 42$ \\
Grade 2 & $18 / 8$ & $14 / 9$ \\
Grade 3 & $9 / 8$ & $9 / 4$ \\
Grade 4 & & \\
\hline
\end{tabular}

*For the 39 children on twice daily insulin.

$\mathrm{p}=0.05$ ). Fasting blood glucose was $0.76 \mathrm{mmol} / \mathrm{l}$ (95\% CI -0.86 to $2 \cdot 38$ ), and serum fructosamine was $0.03 \mathrm{mmol} / \mathrm{l}(95 \% \mathrm{CI}-0.3$ to 0.33$)$ lower on than the isophane based regimen; these differences were not significant at the $5 \%$ level.

The mean (SD) insulin and glucose values for the five children who had 24 hour profiles are shown for the two insulin regimens in table 3. Variation in insulin values as indicated by within individual standard deviation was greater in all five children on the lente regimen and variation in blood glucose values was higher in four of the five children, being highest in the morning.

The frequency of hypoglycaemic episodes was similar on both regimens: the number of grade 1 or 2 episodes was slightly increased on the lente based regimen, whereas the number of grade 3 or 4 episodes was greater on the isophane based regimen (table 2).

Forty one children completed the questionnaires of whom 40 stated their preference for insulin regimen (table 4). Twenty seven of $\mathbf{4 0}$ children (68\%) stated that they preferred isophane to lente insulin, irrespective of the insulin regimen that they were taking at the time they completed the questionnaire (table 4). Symptoms and signs of hyperglycaemia including polyuria, polydipsia, nausea, presence of urinary ketones, and high blood glucose values were reported twice as frequently on the lente compared with the isophane based regimen. In addition, $31 / 41$ (76\%) on lente compared with $18 / 41(44 \%)$ on isophane insulin regimens perceived their blood glucose values to be very erratic $\left(\chi^{2}=8.9, p<0.03\right)$ and only $5 / 41$ children $(12 \%)$ perceived their blood glucose concentrations to be steady between 4.5 and $9 \mathrm{mmol} / \mathrm{l}$ on the lente insulin regimen compared with $18 / 41$ children $(44 \%)$ on the isophane insulin regimen. In all, $63 \%$ of those who preferred isophane insulin gave perceived improvement of metabolic control as their main reason for the preference.
Table 4 Preference for insulin regime from retrospective questionnaire

\begin{tabular}{lllll}
\hline & \multicolumn{2}{l}{ Insulin preference } & \multicolumn{2}{c}{ Total } \\
\cline { 2 - 4 } & Lente & Isophane & 'Don't mind' & \\
\hline $\begin{array}{lllll}\text { Starting insulin: } \\
\text { IIsphane }\end{array}$ & 1 & 16 & 5 & 22 \\
Lente & 4 & 11 & 3 & 18 \\
\hline Total & $5(12 \%)$ & $27(68 \%)$ & $8(20 \%)$ & 40 \\
\hline
\end{tabular}

Significantly more problems with hypoglycaemic episodes were perceived on the lente based regimen (median difference in score +12 , interquartile range 0 to $38, \mathrm{p}<0.01$ ) and children reported lower levels of energy (median 0 , interquartile range +6 to $-17, \mathrm{p}<0.01$ ) on the lente than on the isophane insulin. Median irritability score was also higher on lente than isophane insulin (median score +0.5 , interquartile range -7 to $+26, p=0 \cdot 07)$.

\section{Discussion}

This double blind crossover study in children with IDDM demonstrates lower glycated haemoglobin on an isophane/soluble insulin regimen compared with a lente/soluble insulin regimen. Although the differences in fructosamine and fasting blood glucose measurements between the regimens were small, values were lower with the isophane than with the lente based regimens and the high within individual variation in fasting blood glucose concentration renders this measure open to the possibility of a type 2 error (that is, failure to detect a significant difference when one exists) in a study of this size.

There have been few studies comparing human isophane and lente based insulin regimens in individuals with IDDM, and none have been performed in children. Our results contrast with those of Tunbridge $e t a l$ in the only adult study with sufficient statistical power to effectively compare the two regimens who observed similar fasting blood glucose, variation in blood glucose and glycated haemoglobin on the two regimens. ${ }^{9}$ Corcoren and Yudkin ${ }^{3}$ and Oswald and Yudkin ${ }^{7}$ compared isophane and lente based regimens as well as pork and human insulin regimens in adults with IDDM, and found no significant differences; however, the numbers in the subsets studied were very small.

Eighty percent of the children in this study were previously on pork insulin. Equal numbers of children were randomly allocated to receive either lente or isophane insulin at the beginning

Table 3 Mean (SD) of 12 plasma insulin and glucose estimations taken every two hours over 24 hours in five children on isophane and lente based insulin regimes

\begin{tabular}{|c|c|c|c|c|c|c|c|c|}
\hline \multirow{3}{*}{$\begin{array}{l}\text { Case } \\
\text { No }\end{array}$} & \multicolumn{4}{|c|}{ Insulin dose (units) } & \multirow{2}{*}{\multicolumn{2}{|c|}{$\begin{array}{l}\text { Insulin } \\
\text { (pmol/l) }\end{array}$}} & \multirow{2}{*}{\multicolumn{2}{|c|}{$\begin{array}{l}\text { Blood glucose } \\
\text { (mmol/l) }\end{array}$}} \\
\hline & \multicolumn{2}{|c|}{ Isophane:soluble } & \multicolumn{2}{|c|}{ Lente:soluble } & & & & \\
\hline & $a m$ & pm & $a m$ & $p m$ & Isophane & Lente & Isophane & Lente \\
\hline $\begin{array}{l}1 \\
2 \\
3 \\
4 \\
5\end{array}$ & $\begin{array}{l}36: 4 \\
20: 4 \\
16: 0 \\
26: 14 \\
20: 6\end{array}$ & $\begin{array}{r}10: 4 \\
12: 2 \\
8: 0 \\
18: 8 \\
6: 2\end{array}$ & $\begin{array}{l}36: 4 \\
23: 2 \\
18: 0 \\
26: 12 \\
20: 6\end{array}$ & $\begin{array}{r}10: 4 \\
10: 2 \\
8: 0 \\
16: 8 \\
4: 2\end{array}$ & $\begin{array}{rr}212 \cdot 4 & (105 \cdot 5) \\
185 \cdot 1 & (64.6) \\
83.2 & (35.9) \\
160 \cdot 0 & (51 \cdot 7) \\
203 \cdot 1 & (89.0)\end{array}$ & $\begin{array}{r}189 \cdot 4(132 \cdot 0) \\
199.9(163.6) \\
85.4(39 \cdot 5) \\
207.4(62.4) \\
205.9(122.7)\end{array}$ & $\begin{array}{r}9 \cdot 6(5 \cdot 9) \\
9 \cdot 1(4 \cdot 2) \\
18 \cdot 5(4 \cdot 3) \\
7 \cdot 4(4 \cdot 1) \\
11 \cdot 0(3 \cdot 4)\end{array}$ & $\begin{array}{r}11 \cdot 8(7 \cdot 3) \\
8 \cdot 7(4 \cdot 9) \\
14 \cdot 6(8 \cdot 5) \\
10 \cdot 3(5 \cdot 2) \\
3 \cdot 7(2 \cdot 3)\end{array}$ \\
\hline
\end{tabular}


of the study and no effect of regimen order was observed. It is unlikely that the change to human insulin affected the differences observed between isophane and lente insulins, although it is of interest to note that despite being in a trial, glycated haemoglobin rose on both regimens compared with baseline.

In this study, $30 \%$ of children were positive for $C$ peptide. When only children negative for $C$ peptide were included in the analysis, however, the decrease in glycated haemoglobin on the isophane insulin regimen was similar to that obtained when all children were included. It is possible that the difference between our results and those of the adult studies are due to differences in factors such as insulin absorption kinetics and the presence of a different hormonal environment in children compared with adults.

The increased prevalence of hyperglycaemic symptoms and the increased variability of blood glucose concentrations perceived by the children and parents who completed the retrospective questionnaire agree with the increased glycated haemoglobin and increased variation of free insulin and blood glucose concentrations observed on the lente based regimen. In contrast, although data from the retrospective questionnaire indicated that more problems with hypoglycaemia were perceived on the lente regimen, data collected prospectively throughout the trial showed no significant difference in the frequency of hypoglycaemic episodes between the two regimens. A possible explanation for this apparent discrepancy may be that in the questionnaire, parents and children were asked to express the degree to which hypoglycaemia was a problem on each insulin regimen using a visual analogue scale and not specifically about frequency of hypoglycaemic episodes. Thus other factors such as degree of warning before having a hypoglycaemic attack and timing of attacks may have influenced their response. More detailed study would be required to further investigate this question.

Finally, answers to subjective questions about well being, irritability, and energy levels, in addition to the fact that $67 \%$ of children chose to receive isophane insulin and only $12 \%$ chose to receive lente insulin after the end of the trial, indicate that isophane insulin is the more acceptable intermediate acting insulin for children.

We conclude that human isophane when used in a once or twice daily regimen together with soluble insulin results in better metabolic control, less diurnal variation in free insulin concentration, and is more acceptable to children than human lente insulin. We therefore suggest that this should be the intermediate insulin of first choice in the treatment of children with IDDM.

We thank Dorothy Harris for her help with assaying fructosamine and free insulin samples, Dr Julie Edge and Dr Fiona Campbell samples.

1 Heine RJ, Bilo HGJ, Sikkenk AC. Mixing short and intermediate acting insulins in the syringe: effect on postprandial blood glucose concentration in type I diabetics. Br Med ₹ 1985;290:204-5.

2 Francis AJ, Hanning I, Alberti KGMM. The effect of mixing human soluble and human crystalline zinc-suspension
insulin: plasma insulin and blood glucose profiles after insulin: plasma insulin and blood glucose profiles after
subcutaneous injection. Diabetic Medicine 1985;2:177-80.

3 Corcoran JS, Yudkin JS. A comparison of premixed with patient-mixed insulins. Diabetic Medicine 1986;3:246-9.

patient-mixed insulins. Diabetic Medicine 1986;3:246-9.
4 Francis AJ, Home PD, Walford S, Alberti KGMM, Mann N, Reeves WG. Prevalence of morning hyperglycaemia: determinants of fasting blood glucose concentrations in insulintreated diabetics. Diabetic Medicine 1985;2:89-94.

5 Gale E, Kurtz A, Tattersall R. In seach of the Somogyi effect. Lancet 1980;ii:279-82.

6 Francis AJ, Home PD, Hanning I, Alberti KGMM, Tunbridge WMG. Intermediate acting insulin given at bedtime: effect on blood glucose concentrations before and after breakfast. $\mathrm{Br}$ Med F 1983;286:1173-6.

7 Oswald GA, Yudkin JS. A within patient cross-over trial of 4 insulin regimens in antibody negative, $C$-peptide negative insulin regimens in antibody negative,
patients. Diabetes Res 1987;4:85-98.

patients. Diabetes Res 1987;4:85-98.
8 Home PD, Mann NP, Hutchinson AS, et al. A fifteen-month double-blind cross-over study of the efficacy and antigenicity of human and pork insulins. Diabetic Medicine 1984;1:93-98.

9 Tunbridge FKE, Newens A, Home PD, et al. Double-blind crossover trial of isophane (NPH) and lente-based insulin regimens. Diabetes Care 1989;2:115-9.

10 Kay JDS, Stradling S, Strang S, Dunger DB. Glycated haemoglobin in specimens collected by fingerprick from children: performance data, comparison specimens and reference values. Ann Clin Biochem 1988;25:595-6.

11 Collins ACG, Pickup JC. Sample preparation and radioimmunoassay for circulating free and antibody bound inmulin concentrations in insulin treated diabetics: an insulin concentrations in insulin treated diabetics: an

12 Albano JDM, Ekins RP, Maritz G, Turner RC. A sensitive, precise radioimmunoassay of serum insulin relying on charcoal separation of bound and free horm
Acta Endocrinol (Copenh) 1972;70:487-509.

13 Sandler J. A test of the significance of the differences between Sandler J. A test of the significance of the differences between
the means of correlated measures based on a simplification the means of correlated measures based on a
of Student's t. Br $\mathcal{F}$ Psychol 1955;46:225-6. 